\title{
Rewards and Challenges of Research in a Surgical Career
}

\section{Compensações e Desafios da Investigação numa Carreira Cirúrgica}

Henrique ALEXANDRINO $\triangle^{1,2,3}$

Acta Med Port 2018 May;31(5):235-237 - https://doi.org/10.20344/amp.10697

Keywords: Biomedical Research; Portugal; Specialties, Surgical

Palavras-chave: Especialidades Cirúrgicas; Investigação Biomédica; Portugal

Although Medical Science is a branch of Life Sciences, clinical practice is often separated from research activity. In fact, Science is something clinicians read about and welcome as the main contributor to improved patient care. However, in most instances clinicians seldom have an intrinsic desire to commit with research. The lack of incentives to pursue research in the present productivity-based organizations, the absorbing clinical tasks and the pressing need to keep up with the constantly expanding medical literature are likely factors in the dissociation of clinical and research work. This could be particularly aggravated in surgical disciplines. After all, surgeons are faced with an imperative need to attain and maintain a high level of technical expertise, requiring long hours of operative work. To compound this, there are increasing restrictions on working hours for physicians-intraining and surgical disciplines are the most commonly affected. ${ }^{1}$

All the above-mentioned factors obstruct the alliance of clinical and research activities in surgical disciplines. However, there are exceptions, and potentially numerous rewards, which will be summarily reviewed below.

First, time spent in research should not be viewed as time wasted regarding the maintenance of surgical skills. Not only will research enhance organization skills, task planning and performance but it might actually improve surgical dexterity, especially in research involving microsurgical techniques. ${ }^{2}$

Furthermore, any participation in research will aid in the development of critical reasoning and a more interrogative attitude towards everyday clinical practice. Questions such as "Why are things done this way?" and "How can we improve results?" constantly arise and prompt a critical attitude in practising surgeons. Such curiosity can and should be nurtured, as it will likely drive the development of innovative solutions. An illustrative example is the pancreatic anastomosis, for long considered the "Achilles's heel" of resection of the head of the pancreas. This is because dehiscence of the pancreatic anastomosis is not only the most frequent complication of pancreatic head resection but also the main cause of postoperative mortality. ${ }^{3}$ Although pancreaticoduodenectomy or Whipple's procedure has been described in its current form 70 years ago, ${ }^{4}$ quite a large number of technical variations on the pancreatic anastomosis have been described, of which none is evidently superior so far. Consequently, several trials are still emerging, proving that surgeons can be a major driving force behind research in a clinically relevant problem. ${ }^{5}$

A commitment to research also enables the development of a critical appreciation of the literature and proper evaluation of different levels of evidence. Moreover, by analysing studies from a broader literature base, the surgeon-investigator will likely read novel and exciting research; for instance, laboratory studies using methods usually outside the scope of the mainstream clinical literature, such as genomics, proteomics and metabolism, and using either animal models or cell and tissue cultures. However, extrapolation of these findings to the clinical setting should occur with great caution, as not all conclusions drawn on animal studies are valid in humans. Nonetheless, these studies can open new and interesting avenues for clinical research.

One of the most exciting advantages of research in Surgery is the opportunity for multidisciplinary and interdisciplinary research. By interacting with other clinical disciplines, such as Radiology or Pathology, the surgeonresearcher will often step out of the 'comfort zone' and create new opportunities. Quite specific to all surgical areas is the close collaboration with engineering sciences in the development of new surgical technology. ${ }^{6}$ Also, by working alongside with fellow investigators in the Basic Sciences, surgeons can vastly expand the scope of research in a mutually beneficial way. On a personal note this can be a particularly rewarding experience, whereby the surgeon gains an innovative and interesting insight on a subject, changes perspective and meets investigators of seemingly different backgrounds to work on common clinical problems. In fact, unlike 'pure' basic science researchers or 'pure' clinicians, a surgeon might be particularly apt at applying basic biologic principles in the clinical arena, and vice-versa, articulating these two seemingly distinct perspectives. ${ }^{7}$

1. Faculdade de Medicina. Universidade de Coimbra. Coimbra. Portugal.

2. Serviço de Cirurgia A. Centro Hospitalar e Universitário de Coimbra. Coimbra. Portugal

3. Editor-Associado. Acta Médica Portuguesa. Lisboa. Portugal.

$\square$ Autor correspondente: Henrique Alexandrino. halexandrino123@gmail.com

Recebido: 20 de abril de 2018 - Aceite: 07 de maio de 2018 | Copyright $\odot$ Ordem dos Médicos 2018 
Participation in research will hopefully lead to the publication of findings. This will promote both the individual surgeon-researcher as well as his/her and organizations' curricula (both in academic and non-academic settings). A self-feeding loop of further research and publication can be created in this way. Furthermore, junior surgeons can be more easily mentored into science if a research-oriented environment already exists in their departments. Likewise, experienced surgeon-investigators can also more easily lead their mentees through a successful two-sided surgical and research career. ${ }^{7}$

Finally, the two most important goals of research are: the progression of knowledge and thus the promotion of better patient care; and science and discovery in itself. Although the former is the ultimate aim of all biomedical research, the latter ensures one of the most rewarding consequences of research, being able to satisfy the intrinsic human curiosity on natural phenomena.

However, several challenges stand in the way of surgeons-investigators. One of the most obvious, and possibly the most important, is the ethical issue of human research. Although all clinical studies are under strict control by independent review boards that ensure the cardinal principle of Medicine of primum non nocere, a new challenge emerges, which is the use of patients' personal data in today's society of information. A word of caution is warranted and clinicians should ensure informatic safeguards on patients' data. ${ }^{8}$

A seemingly unsurmountable obstacle for surgeons involved in research is time management. In fact, time for research usually means less time spent on clinical activities. How can surgeons attain and maintain high levels of surgical proficiency while doing research? The answer probably lies with devoting time for research as part of the surgeon schedule. However, this leads to another question: how can organizations, mostly managed on clinical productivity, accommodate this? The answer is not simple but should entail the use of bibliometrics and other proxy indicators of scientific achievement as barometers of productivity. Thus, departments can not only be evaluated on the basis of the clinical work but also on the quantity and especially quality of scientific production. ${ }^{9}$ However, this will inevitably require considerable flexibility of departments in allowing collaborators to define their schedule.

Another hurdle to surgeon-performed research is common to any medical research, i.e. funding. Nowadays
Science is an expensive endeavour and funding relies mostly on grants, driving a highly competitive dispute among laboratories and institutions. This can lead to underfunding of original, surgeon-led research, especially when involving interdisciplinary research because of the so called 'interdisciplinary bias', meaning a bias against research that the grant reviewer will have difficulty in grasping. ${ }^{10}$ Thus, original and truly innovative ideas may lose against more mainstream projects. Surgeons should adapt and, as any other researcher, develop skills in project design and presentation of grant proposals. Furthermore, the association with already established laboratories and academic institutions is paramount.

But how a can a surgeon find, or indeed create new, productive consortia of academic, commercial and clinical organizations dedicated to research? This is likely the most difficult challenge. An aversion, or at least disinclination, towards basic science was fairly common in clinicaloriented congresses. The times are changing though, and nowadays many congresses have sessions dedicated to basic scientific research, ${ }^{11}$ providing the opportunity for surgeons and surgical residents to meet investigators in other fields. This is not only necessary but highly desirable, creating unique opportunities for fruitful interdisciplinary research.

In conclusion, it is safe to state that research is rewarding enough per se. Surgeons, particularly but not exclusively in academic settings, should be actively involved in research, either themselves or by collaborating in interdisciplinary research. The author strongly recommends that residents that wish to devote part of their training time to research can be able to adapt their training program. The current policy of Interno-Doutorando of the Fundação para a Ciência e Tecnologia is welcome but much more can be done. ${ }^{12} \mathrm{An}$ active involvement by key stakeholders, such as Ordem dos Médicos, representative scientific societies, academic institutions and clinical departments is warranted.

\section{ACKNOWLEDGEMENTS}

The author wishes to recognize the substantial influence of José Guilherme Tralhão and the late Francisco Castro e Sousa on the development of his dual career of surgeon and researcher.

\section{CONFLICTS OF INTEREST}

The author reports none.

\section{REFERENCES}

1. Lee DY, Myers EA, Rehmani SS, Wexelman BA, Ross RE, Belsley SS, et al. Surgical residents' perception of the 16-hour work day restriction: Concern for negative impact on resident education and patient care $\mathrm{J}$ Am Coll Surg. 2012;215: 868-77.

2. Aller MA, Mendez M, Nava MP, Lopez L, Arias JLA, Arias J. The value of microsurgery in liver research. Liver International. 2009;29:1132-40.

3. Bassi C, Dervenis C, Butturini G, Fingerhut A, Yeo C, Izbicki J, et al. Postoperative pancreatic fistula: an international study group (ISGPF) definition. Surgery. 2005;138:8-13.

4. Are C, Dhir M, Ravipati L. History of pancreaticoduodenectomy: Early misconceptions, initial milestones and the pioneers. HPB. 2011;13:377-

84.

5. Xu J, Ji SR, Zhang B, Ni QX, Yu XJ. Strategies for pancreatic anastomosis after pancreaticoduodenectomy: What really matters? Hepatobiliary Pancreat Dis Int. 2018;17:22-6.

6. Clymer J, Timm R, Tellio K, Welling A, Asher R, Amaral J. Sealing vessels up to $7 \mathrm{~mm}$ in diameter solely with ultrasonic technology. Med Devices Evid Res. 201;7:263.

7. Leeds I, Wick EC. Establishing a successful basic science research program in colon and rectal surgery. Clin Colon Rectal Surg. 2014;27:5864.

8. Khera M. Think like a hacker: insights on the latest attack vectors 
(and security controls) for medical device applications. J Diabetes Sci Technol. 2017;11:207-12.

9. Donato $\mathrm{H}$. Understanding journal evaluation and strategies to increase impact. Rev Port Pneumol. 2016;22:67-9.

10. Manchikanti L, Kaye AD, Boswell M V, Hirsch JA. Medical journal peer review: process and bias. Pain Physician. 205;18:E1-14.
11. Tralhão JG. Research in general surgery. Rev Port Cir. 2016;38:5,6.

12. Fundação para a Ciência e Tecnologia. Formação Doutoral em Investigação Clínica para Internos-Doutorandos [Internet]. 2018. [accessed 2018 Apr 04]. Available from: https://www.fct.pt/apoios/ intdoutorando/. 